\title{
Stock Prediction using Machine Learning a Review Paper
}

\author{
Nirbhey Singh Pahwa \\ Student, Information Technology (I.T.) \\ Vidyalankar Institute of Technology \\ Mumbai, Maharashtra, India. \\ Vidhi Soni \\ Student, Information Technology (I.T.) \\ Vidyalankar Institute of Technology \\ Mumbai, Maharashtra, India
}

\author{
Neeha Khalfay \\ Student, Information Technology (I.T.) \\ Vidyalankar Institute of Technology \\ Mumbai, Maharashtra, India. \\ Deepali Vora \\ Assistant Professor, \\ Information Technology (I.T.) \\ Vidyalankar Institute of Technology \\ Mumbai, Maharashtra, India
}

\begin{abstract}
Every day more than 5000 trade companies enlisted in Bombay stock Exchange (BSE) offer an average of $24,00,00,000+$ stocks, making an approximate of $2000 \mathrm{Cr}+$ Indian rupees in investments. Thus analyzing such a huge market will prove beneficial to all stakeholders of the system. An application which focuses on the patterns generated in this stock trade over the period of time, and extracting the knowledge from those patterns to predict future behavior of the BSE stock market is essential. An application representing the information in visual form for user interpretation to buy and to sell a specific company's stock is a key requirement.

Such an application based on machine learning algorithms is the right choice in current scenario. This paper surveys the machine learning algorithms suitable for such an application; as well it discusses what are the current tools and techniques appropriate for its implementation.
\end{abstract}

\section{General Terms}

Support Vector Machine (SVM), Support Vector Regression (SVR) and stock market.

\section{Keywords}

Machine learning, review paper, stock prediction, machine learning algorithms, supervised learning, unsupervised learning, supervised learning algorithms, regression, classification, regression algorithm, Support Vector Machine (SVM), Support Vector Regression (SVR), classification, linear regression, logistic regression, types of regression, types of classification, types of programming languages for machine learning, types of libraries for machine learning, types of libraries for graphing, types of libraries for analysis.

\section{INTRODUCTION}

Machine learning can be defined as the data which is obtained by knowledge extraction. Machines don't have to be programmed explicitly instead they are trained to make decisions that are driven by data. Instead of writing a code for every specific problem, data is provided to the generic algorithms and logic is developed on the basis of that data. When a machine improves its performance based on its past experiences it can be said that machine has truly learnt.

The technique for most accurate prediction is by learning from past instances, and to make a program to do this is best possible with machine learning techniques. Any machine learning technique (supervised or unsupervised) is efficient enough to generate rules for programs, in consideration with present ones to take a better decision. In this scenario, the decision is whether the stock will increase or decrease (Stock analysis).

\section{MACHINE LEARNING ALGORITHMS}

\subsection{Unsupervised learning}

When the dataset is not well defined or very hard for interpretation, it is called unsupervised learning. The labels for the data are not defined. There no right way to divide data set except performing iterations. Thus, in supervised learning the input is used to generate a structure by looking at the relation of the input itself.

For example, Classification of animals. [4]

According to this research, unsupervised learning is not advisable for prediction.

\subsection{Supervised learning}

Supervised learning can be said as function approximation, training examples lead to function generation. If the learning is done with right training set, a well behaved function can be expected. Supervised learning grows consistently with the data. It is a type of induction learning, and it causes biased supervised learning sometimes.

E.g.: The function generated with supervised learning will be

$X^{2}$, if $\mathrm{X}$ is the input value and the output is self-multiplied.

Since, there is well defined data available from BSE itself and which is in well-defined numeric form it would be beneficial to use supervised learning algorithms. Supervised learning algorithms are of two variants: [3]

\section{Regression. \\ 2. Classification}

\subsubsection{Regression algorithm}

The method of Support Vector Classification (SVC) can be used to solve regression problems. When Support Vector Machine (SVM) is used to solve regression problems the method is referred as Support Vector Regression (SVR).

The model produced by SVC depends only on the training data, because the factor of cost of model building does not care about training points that lie outside the margin 
Similarly, the model produced by SVR only depends on the training (Subset) data, as the cost factor for building the model does not consider any training data close to the model prediction. [5]

\subsubsection{Regression problems Input is mapped by labels.}

\section{Input mapped to large and many data set.}

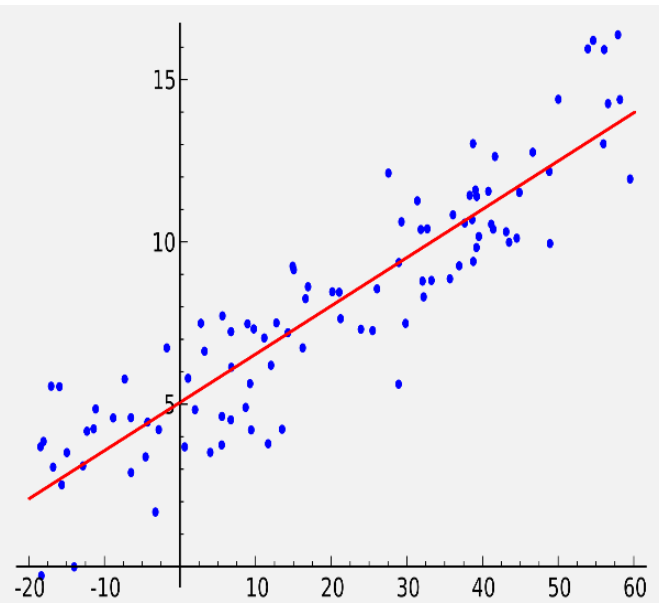

Use regression when the output can be mapped to many outlets.

Figure 1

\subsubsection{Types of regression}

The seven types of regression are briefly explained and compared in the following tables 1 (a) and 1 (b).

\subsubsection{Classification algorithm}

Classification is a type of supervised learning (machine learning) in which some decision is taken or prediction is made on the basis of information which is currently available and the procedure of carrying out classification is a formal method which is used for constantly making such judgements in different and new situations. The formation of a classification method from a data set for which the true classes are known is also known as pattern recognition, supervised learning or discrimination (in order to differentiate it from unsupervised learning in which the classes are always inferred from the data). Classification is used in many situations like the most difficult situations arising in science, industry and commerce can be determined by classification or decision problems which use complex and often very extensive data.

\subsubsection{Classification problems \\ Input is mapped to label.}

Input to small and discreet data set.

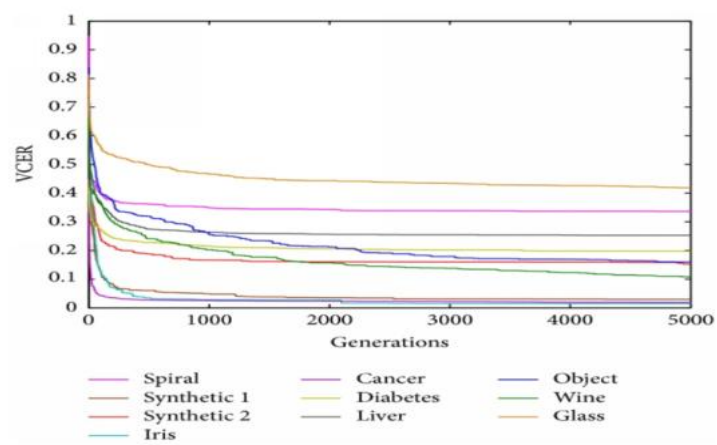

Figure 2

\subsubsection{Types of classification}

The different types of classifications are briefly explained and compared in the following table 2. [7]

\section{ALGORITHMS AND TOOLS FOR THIS SYSTEM}

\subsection{Linear regression}

The most commonly known modelling technique is linear regression. In this technique, the first (dependent variable) is continuous, the second variables (independent variable) can be continuous or discrete and this leads to a linear line which is the nature of this regression.

It establishes a relationship between the first variable (dependent variable (Y)) and one second variables (independent variables $(\mathrm{X})$ ) and making a straight line which is best fit after computation (which is the regression line).

It is given by an equation:

$Y=(a+b) * X+e$, where 'a' is the intercept, ' $\mathrm{b}$ ' is the slope of the line and ' $\mathrm{e}$ ' is the error term. Given equation is also used to predict the value of target variable, on given predictor variable(s)

The major difference between the simple linear regression and multiple regression is that, multiple regression supports more than one independent variables, but simple linear regression has only one independent variable which it can handle.

To obtain best fit line, following procedures are to be done. This can be accomplished by the least square method. It is the most easy and common way for making a regression line. It computes the best-fitting line for the taken data by reducing to the minimum the addition of the squares of the vertical deviations, from each point to the produced line. Since, the deviations are first squared, when summed; positive and negative values do not cancel out.

The following equation is used for calculating the line plotting:

$$
\min (w)\|X w-y\|^{2}
$$

Points to consider before considering linear regression 
- A linear relationship between the given independent and the taken dependent variables is essential.

- It can suffer from multicollinearity, heteroscedasticity, etc.

- Outliers can impact linear regression in a huge way, which can even lead to wrong predictions.

- Step wise approach also uses selection of most significant independent variables.

\subsection{Logistic regression}

It is used to find the probability of how much chance there is for cases such that the event is success and the same event is a failure. Logistic regression can be implemented when the dependent variable is binary (one of two values) in nature, that is, it can have at most two values. In this example the value of ' $\mathrm{Y}$ ' can be 0 to 1 , it is represented by the equation: [9]

Odds $=$ probability of event occurring divided by the probability of event not occurring

$$
\begin{gathered}
\text { Odds }=\frac{\mathrm{p}}{1-\mathrm{p}} \\
\operatorname{Ln}(\text { Odds })=\operatorname{Ln}\left(\frac{P}{1-P}\right) \\
\log (P)=\operatorname{Ln}\left(\frac{P}{1-P}\right)=B 0+(B 1 * 1)+\cdots+(B k * k)
\end{gathered}
$$

Where, $\mathrm{P}$ is the probability of interested characteristic presence. As there is a binomial distribution of dependent variable implemented, there has to be a link function which will be best fitted for the distribution, which is the logit function. The above equation has, the parameters selected to max the chance of getting the sample values instead of minimizing the addition of squared errors (as seen in the ordinary regression). [8]

Points to consider before considering logistic regression:

- It is widely used for classification problems and does not really need linear relationship between the dependent and the independent variables. It can take many different types of relationships since it enforces a non-linear log transformation for predicting the odds ratio.

- To remove over fitting as well as under fitting, all significant variables should be included. A better approach to make sure this practice is by using a step wise method to compute the logistic regression.

- It needs huge sample sizes. Since, maximum likelihood that calculations are less accurate at low sample sizes in comparison to the ordinary least square.

- No multi collinearity i.e. the independent variables need not be inter-related with each other. But there are still options to consider interaction impacts of categorical variables in computation and modelling.

- It will be called as Ordinal logistic regression when the values of dependent variable are ordinal. [6]

\subsection{Tools for implementation}

The different types of development software which can support the system are briefly explained and compared in the following table 3. [1]

The different types of libraries are briefly explained and compared in the following table 4. [2]

The different types of tools are briefly explained and compared in the following table 5.

\section{SYSTEM DIAGRAM}

With above knowledge in consideration and undertaking the tables as reference, a proposed system and its diagram is shown below. The system will work on a comma separated variable (CSV) file, which will have a record of all the dates and its crude data of open, high, low, etc. Out of this crude data, knowledge will be extracted by performing data preprocessing and refining to predict a close information for requested date of future. The CSV files are provided by the BSE itself.

Once the knowledge is available, it will be feed to the SVM algorithm to perform stock prediction and give a data visualization using python, this investment prediction will be sub-divided into different time frames ( months, days, hours) and a suitable advice from the prediction can be obtained by the consumer. The system diagram is as show below:

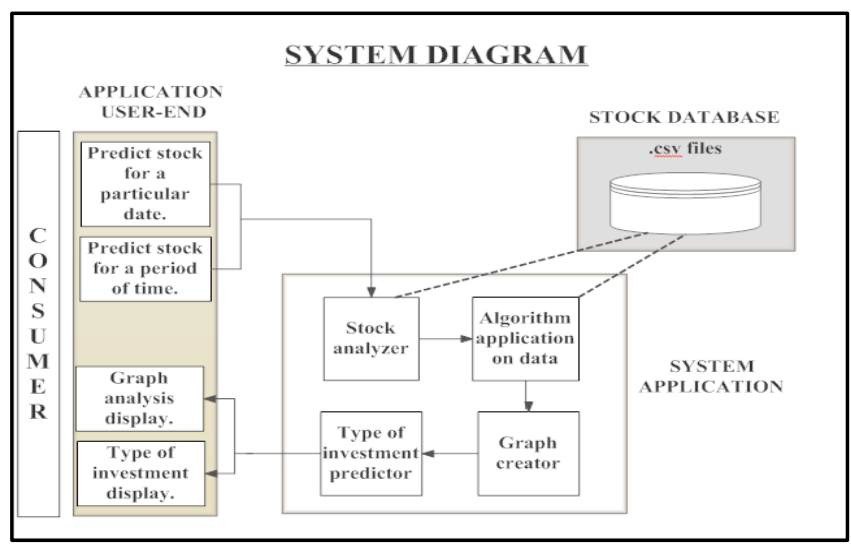

Figure 3

\section{CONCLUSION}

This paper summarizes important techniques in machine learning which are relevant to stock prediction. The paper recommends use of linear regression and logistic regression for stock prediction and stock analysis and this study recommends SVM to obtain accurate results. A constraint to this conclusion is the necessity of the dataset used in prediction to be classification friendly. The paper summarizes the tools which can be used for implementation of machine learning algorithms. All the tools support regression and classification algorithms, users can choose any tool based on their familiarity and convenience. The paper proposes a system to extract knowledge from data and performing a prediction to advise the consumer for investments. 
Table 1 (a): Types of regression

\begin{tabular}{|c|c|c|c|c|}
\hline Properties & Linear regression & Logistic regression & Polynomial regression & Stepwise regression \\
\hline Features & $\begin{array}{l}\text { In this technique, the first } \\
\text { (dependent variable) is } \\
\text { continuous, the second } \\
\text { variables (independent } \\
\text { variable) can be continuous } \\
\text { or discrete, and this leads to a } \\
\text { linear line which is the nature } \\
\text { of this regression. }\end{array}$ & $\begin{array}{l}\text { It is used to find the } \\
\text { probability of how much } \\
\text { chance is there for cases such } \\
\text { that the event is a success and } \\
\text { the same event is a failure. } \\
\text { Logistic regression is used } \\
\text { when the dependent variable is } \\
\text { binary in nature, that is, it can } \\
\text { have at the most two values. }\end{array}$ & $\begin{array}{l}\text { If the power of independent } \\
\text { variable is greater than one, } \\
\text { the regression equation is } \\
\text { called as polynomial } \\
\text { regression. }\end{array}$ & $\begin{array}{l}\text { Stepwise regression is } \\
\text { used when there are many } \\
\text { independent variables. } \\
\text { An automatic process } \\
\text { (steps) is used for the } \\
\text { selection of independent } \\
\text { variables, and no } \\
\text { involvement or human } \\
\text { intervention is needed. }\end{array}$ \\
\hline Advantages & $\begin{array}{l}\text { It is implemented, when } \\
\text { relationships of the } \\
\text { independent variables and } \\
\text { the dependent variable are } \\
\text { linear (almost), and it shows } \\
\text { optimal results. } \\
\text { If the datasets are well } \\
\text { defined, there is no better } \\
\text { regression than linear } \\
\text { regression. }\end{array}$ & $\begin{array}{l}\text { Mostly used in classification } \\
\text { problems. } \\
\text { Linear relationship between } \\
\text { the dependent and the } \\
\text { independent variables is not } \\
\text { necessary. }\end{array}$ & $\begin{array}{l}\text { The best fit line need not be } \\
\text { a straight line. } \\
\text { It is instead a curve which } \\
\text { fits accurately into the data } \\
\text { points. }\end{array}$ & $\begin{array}{l}\text { It includes and excludes } \\
\text { predictors as required for } \\
\text { each step. } \\
\text { The aim of this technique } \\
\text { is to maximize the } \\
\text { prediction power with } \\
\text { minimum numbers of } \\
\text { predictor variables. } \\
\text { Higher dimensionality of } \\
\text { data set can be handled by } \\
\text { this technique. }\end{array}$ \\
\hline Disadvantages & $\begin{array}{l}\text { A linear relationship between } \\
\text { the given independent and } \\
\text { the taken dependent variables } \\
\text { is essential. } \\
\text { It can suffer from } \\
\text { multicollinearity, } \\
\text { heteroscedasticity, etc. }\end{array}$ & $\begin{array}{l}\text { It needs huge sample sizes. } \\
\text { Since, maximum likelihood } \\
\text { calculations are less accurate } \\
\text { at low sample sizes in } \\
\text { comparison to the ordinary } \\
\text { least square. }\end{array}$ & $\begin{array}{l}\text { Higher polynomials can end } \\
\text { up producing weird results } \\
\text { on extrapolation. }\end{array}$ & $\begin{array}{l}\text { It often has many potential } \\
\text { predictor variables but } \\
\text { very less data to estimate } \\
\text { coefficients correctly. } \\
\text { Adding more data does } \\
\text { not help much, if at all. }\end{array}$ \\
\hline
\end{tabular}

Table 1 (b): Types of regression

\begin{tabular}{|c|c|c|c|}
\hline Properties & Ridge regression & Lasso regression & Elastic Net regression \\
\hline Features & $\begin{array}{l}\text { It is a technique used when the data } \\
\text { suffers from multicollinearity. } \\
\text { In multicollinearity, even if the least } \\
\text { squares estimates are not biased, } \\
\text { their variances are huge which } \\
\text { separate the observed value far from } \\
\text { the true value, by involving a bias to } \\
\text { the regression estimates, standard } \\
\text { errors can be reduced. }\end{array}$ & $\begin{array}{l}\text { Lasso regression is Least Absolute } \\
\text { Shrinkage and Selection Operator. } \\
\text { It penalizes the exact size of the } \\
\text { coefficients. } \\
\text { It also is capable of reducing the } \\
\text { variability and improving the accuracy } \\
\text { for the linear regression models. }\end{array}$ & $\begin{array}{l}\text { It is a hybrid of Ridge Regression } \\
\text { and Lasso techniques. } \\
\text { It is trained with L1 and L2 prior as } \\
\text { regularize. Elastic-net is most useful, } \\
\text { if there are multiple features which } \\
\text { are interrelated. }\end{array}$ \\
\hline Advantages & $\begin{array}{l}\text { It diminishes the value of } \\
\text { coefficients but does not reach zero, } \\
\text { which shows the no feature selection } \\
\text { feature. }\end{array}$ & $\begin{array}{l}\text { It shrinks coefficients exactly to zero, } \\
\text { which shows the feature selection. } \\
\text { This is a regularization method and } \\
\text { uses L1 regularization. }\end{array}$ & $\begin{array}{l}\text { It allows Elastic-Net to extend some } \\
\text { of Ridge's stability under rotation. } \\
\text { There is no limit to the number of } \\
\text { selected variables. }\end{array}$ \\
\hline Disadvantages & Normality cannot be assumed. & $\begin{array}{l}\text { If group of predictors are very } \\
\text { interrelated, it picks only one among } \\
\text { all of them and reduces others to zero. }\end{array}$ & $\begin{array}{l}\text { It suffers with double shrinkage } \\
\text { sometimes. } \\
\text { It does encourage group effect when } \\
\text { there is highly correlated variables. }\end{array}$ \\
\hline
\end{tabular}

Table 2: Types of classification

\begin{tabular}{|l|l|l|l|}
\hline Properties & Support Vector Machine (SVM) & Bayesian's Classifier & Decision Tree \\
\hline Definition & $\begin{array}{l}\text { A Support Vector Machine (SVM) } \\
\text { implements classification by finding the } \\
\text { hyperplane that maximizes the margin }\end{array}$ & $\begin{array}{l}\text { The Naïve Bayesian classifier is } \\
\text { classification method based on Bayes' } \\
\text { theorem with independence }\end{array}$ & $\begin{array}{l}\text { Decision tree is used to build } \\
\text { classification models in the form of a } \\
\text { tree structure. It breaks down a }\end{array}$ \\
\hline
\end{tabular}




\begin{tabular}{|c|c|c|c|}
\hline & $\begin{array}{l}\text { between the two classes. The vectors or } \\
\text { cases that represent the hyperplane are } \\
\text { the support vectors. }\end{array}$ & $\begin{array}{l}\text { assumptions between predictors. This } \\
\text { model is easy to build, with no } \\
\text { perplexing iterative parameter } \\
\text { estimation which makes it particularly } \\
\text { useful for very large datasets. Although } \\
\text { it is simple, the Naïve Bayesian } \\
\text { classifier often does surprisingly well } \\
\text { and is widely used because it often } \\
\text { outruns more practiced classification } \\
\text { methods. }\end{array}$ & $\begin{array}{l}\text { dataset into smaller subsets } \\
\text { simultaneously and an associated } \\
\text { decision tree is incrementally } \\
\text { developed. The topmost decision } \\
\text { node in a tree which resembles or } \\
\text { correlates to the best predictor } \\
\text { called root node. Decision trees can } \\
\text { handle both categorical and numerical } \\
\text { data. }\end{array}$ \\
\hline Diagram & $x_{x_{1}}$ & $\begin{array}{ccccc} & \text { Expt }_{1} & \text { Expt }_{2} & \ldots & \text { Expt }_{L} \\
\mathbf{X}_{L}^{1} & x_{1}^{1} & x_{2}^{1} & \ldots & x_{L}^{1} \\
\mathbf{X}_{L}^{2} & x_{1}^{2} & x_{2}^{2} & \ldots & x_{L}^{2} \\
\vdots & \vdots & \vdots & x_{l}^{n} & \vdots \\
\mathbf{X}_{L}^{N} & x_{1}^{N} & x_{2}^{N} & \ldots & x_{L}^{N}\end{array}$ & 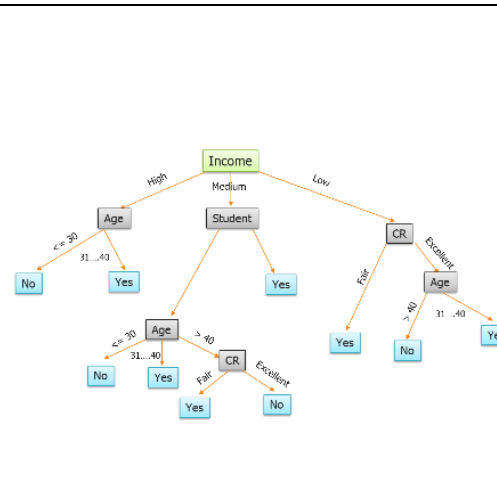 \\
\hline Advantages & $\begin{array}{l}\text { Widen the margin between two classes } \\
\text { in the feature space characterized by a } \\
\text { kernel function. } \\
\text { They are robust with respect to high } \\
\text { input dimension. } \\
\text { High accuracy. } \\
\text { Good for large feature sets. }\end{array}$ & $\begin{array}{l}\text { Easy to implement. } \\
\text { Satisfactory results obtained in most of } \\
\text { the cases. }\end{array}$ & $\begin{array}{l}\text { Easy to understand. } \\
\text { Easy to generate rules. } \\
\text { Reduces problem complexity. }\end{array}$ \\
\hline Disadvantages & $\begin{array}{l}\text { Difficult to combine background } \\
\text { knowledge. } \\
\text { Sensitive to outliers. } \\
\text { Hard to interpret. } \\
\text { Memory-intensive. }\end{array}$ & $\begin{array}{l}\text { Assumptions: Class conditional } \\
\text { independence, which causes loss of } \\
\text { accuracy. } \\
\text { Practically, dependencies exist among } \\
\text { variables which cannot be modelled by } \\
\text { Naïve Bayesian Classifier. }\end{array}$ & $\begin{array}{l}\text { Training time is comparatively } \\
\text { expensive. } \\
\text { A document is only connected with } \\
\text { one branch. } \\
\text { While constructing the tree, once a } \\
\text { mistake is made at a higher level node } \\
\text { of the tree, any sub-tree below it is } \\
\text { wrong. } \\
\text { Does not handle continuous variable } \\
\text { properly. } \\
\text { May suffer from overfitting. }\end{array}$ \\
\hline
\end{tabular}

Table 3: Tools (Types of programming language)

\begin{tabular}{|c|c|c|c|c|}
\hline Properties & Python & Java & $\mathbf{R}$ & .Net \\
\hline Features & $\begin{array}{l}\text { Free and Open Source. } \\
\text { It is a high-level language. } \\
\text { It provides portability. } \\
\text { It is interpreted. } \\
\text { It provides extensive } \\
\text { libraries. }\end{array}$ & $\begin{array}{l}\text { Platform independent. } \\
\text { Portable. } \\
\text { Multi-threaded. } \\
\text { Distributed. } \\
\text { Robust. }\end{array}$ & $\begin{array}{l}\text { Free and Open Source. } \\
\text { Flexible and powerful. } \\
\text { It is cross-platform. } \\
\text { Interactive language. } \\
\text { Ease due to the package } \\
\text { system. }\end{array}$ & $\begin{array}{l}\text { Windows application. } \\
\text { Console application. } \\
\text { Languages supported } \\
\text { IntelliSense Assemblies. }\end{array}$ \\
\hline
\end{tabular}




\begin{tabular}{|c|c|c|c|c|}
\hline & Indentation. & & & \\
\hline Advantages & $\begin{array}{l}\text { Efforts required to write a } \\
\text { program in Python is less as } \\
\text { compared to other languages. } \\
\text { Portable. } \\
\text { Its integration with other } \\
\text { languages like C/C++. } \\
\text { Python being a general } \\
\text { purpose language helps us } \\
\text { attain maximum flexibility. } \\
\text { Its emphasis on productivity } \\
\text { and easiness in readability. }\end{array}$ & $\begin{array}{l}\text { Elimination of pointers and } \\
\text { the replacement of the } \\
\text { complex multiple inheritance } \\
\text { by interface provides } \\
\text { simplicity. } \\
\text { The "Write Once Run } \\
\text { Anywhere" feature provided } \\
\text { by Java Networking capability } \\
\text { i.e. the distributiveness } \\
\text { Reliability i.e. the robustness } \\
\text { offered by Java. }\end{array}$ & $\begin{array}{l}\text { Free and Open Source } \\
\text { Graphical capabilities. } \\
\text { Packages available for data } \\
\text { mining, spatial analysis. } \\
\text { It can easily import data } \\
\text { from CSV les, SAS, SPSS } \\
\text { or from Microsoft Excel, } \\
\text { MySQL or SQLite directly. } \\
\text { Graphics output in the form } \\
\text { of PNG, PDF, JPG and SVG } \\
\text { formats and table output for } \\
\text { LATEX and HTML is } \\
\text { provided by R. }\end{array}$ & $\begin{array}{l}\text { Compatible with multiple } \\
\text { languages. } \\
\text { Ease in interfacing with } \\
\text { Microsoft or Windows } \\
\text { Seamless integration of } \\
\text { language. } \\
\text { The drag and drop } \\
\text { capability as well as the } \\
\text { blueprints offered. } \\
\text { Easiness provided by the } \\
\text { separation of the HTML } \\
\text { code from the source code. }\end{array}$ \\
\hline Disadvantages & $\begin{array}{l}\text { Pace decreases as it is an } \\
\text { interpreted language. } \\
\text { Design of the language is a } \\
\text { drawback since the testing } \\
\text { required is more and the } \\
\text { errors are shown during the } \\
\text { runtime. } \\
\text { Absence felt in mobile } \\
\text { computing and browsers } \\
\text { because of security. }\end{array}$ & $\begin{array}{l}\text { Since it is a multi-platform } \\
\text { language, it is slow and also } \\
\text { occupies more memory space. } \\
\text { Problems caused for low level } \\
\text { programming. } \\
\text { Limitations for applet caused } \\
\text { due to security. }\end{array}$ & $\begin{array}{l}\text { Poses difficulty for the } \\
\text { unexperienced users. } \\
\text { Provides several simple } \\
\text { GUIs which include point } \\
\text { and click interactions but } \\
\text { lacks to deliver the } \\
\text { commercial offerings. } \\
\text { R commands occupy all the } \\
\text { available memory which is a } \\
\text { drawback while doing data } \\
\text { mining. }\end{array}$ & $\begin{array}{l}\text { Does not support multi- } \\
\text { platform. } \\
\text { Excessive use of system } \\
\text { resources. } \\
\text { Application pauses from } \\
\text { execution due to garbage } \\
\text { collection. } \\
\text { Installation process has to } \\
\text { be manually done since it } \\
\text { is not predefined. }\end{array}$ \\
\hline
\end{tabular}

Table 4: Tools (Types of library for analysis)

\begin{tabular}{|c|c|c|c|c|}
\hline Properties & Scikit-learn & Pandas & Theano & NLTK \\
\hline Features & $\begin{array}{l}\text { Tools available for data } \\
\text { analysis and mining. } \\
\text { Primary focus } \\
\text { modelling of data. } \\
\text { Open source and can be } \\
\text { used commercially. } \\
\text { Built using SciPy, } \\
\text { matplotlib and NumPy. } \\
\text { Accessibility to one and } \\
\text { all. } \\
\text { Reusability. }\end{array}$ & $\begin{array}{l}\text { It provides label for data. } \\
\text { The table format for data } \\
\text { which includes label for } \\
\text { columns and indexed rows. }\end{array}$ & $\begin{array}{l}\text { Integrated with NumPy. } \\
\text { Optimizes speed and } \\
\text { stability. } \\
\text { Ability to perform derivative } \\
\text { for functions with more than } \\
\text { one input. } \\
\text { Self-verification and unit } \\
\text { testing. } \\
\text { High-speed performance. }\end{array}$ & $\begin{array}{lr}\text { Freely and } & \text { openly } \\
\text { available } & \\
\text { It provides } & \text { Python } \\
\text { program } & \text { which } \\
\text { incorporates } & \text { human } \\
\text { language data. } \\
\text { Interface having an ease of } \\
\text { use provides many } \\
\text { resources, text processing } \\
\text { libraries for parsing, } \\
\text { tagging, classification, } \\
\text { tokenization, stemming } \\
\text { and semantic reasoning. } \\
\text { It has predefined graphical } \\
\begin{array}{lr}\text { demonstrations } \\
\text { sample data. }\end{array}\end{array}$ \\
\hline Advantages & $\begin{array}{l}\text { Cleanliness offered by the } \\
\text { API design. } \\
\text { Robustness. } \\
\text { High speed. } \\
\text { Ease of Use. } \\
\text { Well documented. } \\
\text { Active development and } \\
\text { well supported. }\end{array}$ & $\begin{array}{l}\text { Easy to perform an operation } \\
\text { since Pandas provide table } \\
\text { format for data. } \\
\text { Supports different data types. } \\
\text { Built-in functionality for many } \\
\text { data processing applications. } \\
\text { Due to its support in storage } \\
\text { and memory functions, large } \\
\text { scale of data can be handled. }\end{array}$ & $\begin{array}{l}\text { It provides differentiation } \\
\text { automatically even when it } \\
\text { is not needed. } \\
\text { Numpy's syntax is supported } \\
\text { and borrowed by its mature } \\
\text { and an intuitive tensor } \\
\text { interface. } \\
\text { It saves a lot of development } \\
\text { time which helps one to } \\
\text { focus on one's system rather }\end{array}$ & $\begin{array}{l}\text { It is fully self-contained. } \\
\text { It provides raw versions of } \\
\text { real-world data in the form } \\
\text { of trained models as well } \\
\text { as functions that can be } \\
\text { used as building blocks for } \\
\text { common NLP tasks. }\end{array}$ \\
\hline
\end{tabular}




\begin{tabular}{|c|c|c|c|c|}
\hline & & & $\begin{array}{l}\text { than concentrating on } \\
\text { optimizing graphs. }\end{array}$ & \\
\hline Disadvantages & $\begin{array}{l}\text { Restrictions on choice of } \\
\text { language. } \\
\text { Not scalable enough. }\end{array}$ & $\begin{array}{l}\text { Addition of syntactic noise. } \\
\text { The list throws away an extra } \\
\text { holding space which is } \\
\text { temporary for the values } \\
\text { which are common to stay } \\
\text { with the Pandas data frame. }\end{array}$ & $\begin{array}{l}\text { Graph optimization results } \\
\text { in the increase in the } \\
\text { compilation time. } \\
\text { Theano scan are really slow } \\
\text { in speed. }\end{array}$ & $\begin{array}{l}\text { It has to work with } \\
\text { different variable types. } \\
\text { Mandatory usage of } \\
\text { regular expressions, } \\
\text { tagging, stemming, } \\
\text { chunking and context-free } \\
\text { and feature based } \\
\text { grammars. } \\
\text { Raw text needs to be } \\
\text { processed. } \\
\text { It has to discover parts of } \\
\text { speech tags. }\end{array}$ \\
\hline
\end{tabular}

Table 5: Tools (Types of library for graphing)

\begin{tabular}{|c|c|c|c|}
\hline Properties & Matplot lib & plot.ly & Bokeh \\
\hline Features: & $\begin{array}{l}\text { Works with labelled data similar to } \\
\text { DataFrames in Panda.s } \\
\text { Not only can it cycle colors but also } \\
\text { line styles and hatches. } \\
\text { Provides selection for backend } \\
\text { Integration with LaTeX. } \\
\text { It can have multiple plots on the same } \\
\text { axes. } \\
\text { Multiple subplots can be obtained in a } \\
\text { single figure. } \\
\text { 3D plotting. }\end{array}$ & $\begin{array}{l}\text { It is an online analytics and data } \\
\text { visualization tool. } \\
\text { Online graphing, analytics, and } \\
\text { statistics tools are provided not only } \\
\text { for individuals/collaboration, as well as } \\
\text { scientific graphing libraries for Python } \\
\text { Its graphical user interface which } \\
\text { provides stats tools for analyzing and } \\
\text { importing data into a grid. } \\
\text { To create graphs more efficiently, they } \\
\text { can be either embedded or } \\
\text { downloaded. } \\
\text { Responsible for providing API libraries } \\
\text { for Python, MATLAB, R, Julia, } \\
\text { Node.js and Arduino } \\
\text { It helps with styling interactive graphs } \\
\text { using IPython. } \\
\text { Apps developed using Plotly for } \\
\text { Google Chrome. } \\
\text { Graphs and dashboards are created } \\
\text { using the open source JavaScript } \\
\text { library. }\end{array}$ & $\begin{array}{l}\text { It provides elegant construction of } \\
\text { novel graphics in the D3.js style and } \\
\text { provides extension of this function } \\
\text { to large or streaming datasets along } \\
\text { with ugh performance. } \\
\text { It provides aid to create interactive } \\
\text { plots, data applications and } \\
\text { dashboards efficiently. } \\
\text { Its syntax is similar to R/ggplot } \\
\text { users. } \\
\text { It is fully open-sourced. }\end{array}$ \\
\hline Advantages: & $\begin{array}{l}\text { Default plot styles are available with } \\
\text { built-in code. } \\
\text { Deep integration with Python. } \\
\text { The programming interface is Matlab- } \\
\text { style. }\end{array}$ & $\begin{array}{l}\text { Allowance for changing the colors and } \\
\text { style for the graph. } \\
\text { Also allows to change the plot type. } \\
\text { Title for the graph and label for the } \\
\text { axes can be provided. } \\
\text { Hovering the mouse cursor on the line } \\
\text { will provide the values of the points. }\end{array}$ & $\begin{array}{l}\text { It provides visualization library that } \\
\text { targets web browsers for } \\
\text { presentation. }\end{array}$ \\
\hline Disadvantages: & $\begin{array}{l}\text { It is unpredictable for dynamic, } \\
\text { interactive plots. } \\
\text { Very much reliant on packages like } \\
\text { Numpy. } \\
\text { It works only for Python. }\end{array}$ & $\begin{array}{l}\text { This technology is relatively new. } \\
\text { It requires internet for viewing data } \\
\text { into graphical representation. }\end{array}$ & $\begin{array}{l}\text { Community support not prompt. } \\
\text { Relatively new library with no } \\
\text { history for credibility. }\end{array}$ \\
\hline
\end{tabular}




\section{REFERENCES}

[1] Author: W. HuangResearch paper: Forecasting stock market movement direction with support vector machine.Journal: Computers \& Operations Research

[2] Author: J. MoodyResearch paper: Learning to trade via direct reinforcement. Journal: IEEE Transactions on Neural Networks

[3]https://www.analyticsvidhya.com/blog/2015/08/comprehen sive-guide-regression/

[4]https://azure.microsoft.com/enin/documentation/articles/machine-learning-algorithmchoice/

[5] Author: Yusuf Perwej, Asif PerwejResearch paper: Prediction of the Bombay Stock Exchange (BSE) Market Returns Using Artificial Neural Network and Genetic Algorithm.Journal: Scientific Research

[6] Author: K. Senthamarai Kannan, P. Sailapathi Sekar,M.Mohamed Sathik and P. Arumugam Research paper: Financial Stock Market Forecast using Data
MiningTechniquesJournal: International MultiConference of Engineers and Computer Scientists 2010 Vol I,IMECS 2010, March 17-19,2010, Hong Kong.ISSN:2078-0966

[7] Author: Zahid Iqbal, R. Ilyas, W. Shahzad, Z. Mahmood and J AnjumResearch paper: Efficient Machine Learning Techniques forStock Market PredictionJournal: Int. Journal of Engineering Research and Applications, ISSN: 2248-9622, Vol. 3, Issue 6, Nov-Dec 2013, pp.855-867.

[8] Author: Marc-André MittermayeResearch paper: Forecasting Intraday Stock Price Trends with Text Mining TechniquesJournal: Hawaii International Conference on System Sciences -2004.

[9] Author: Prakash Ramani, Dr. P. D. MurarkaResearch paper: Stock Market Prediction Using Artificial Neural NetworkJournal: International Journal of Advanced Research in Computer Science and Software Engineering. ISSN: 2277-128x, Volume 3, Issue 4, April 2013 